\title{
Didactic Atlas of the National Geographic Institute of Spain
}

\author{
Ana Velasco Tirado ${ }^{\text {a, } * \text {, Celia Sevilla Sánchez }}{ }^{\text {a }}$, Noelia Esther Aguiar Rivero ${ }^{\text {a }}$ \\ ${ }^{a}$ National Centre of Geographic Information (National Geographic Institute of Spain), ana.velasco@cnig.es, celia.sevilla@cnig.es, \\ noelia.aguiar@cnig.es \\ * Corresponding author
}

Keywords: Didactic Atlas, Geography, Teaching and learning material, Open Educational Resource

Abstract:

The National Geographic Institute of Spain (IGN) is creating a new open online educational resource for the teaching community. It is a Didactic Atlas that consists of a set of materials to support the teaching of Geography at Secondary and High School.

This new Didactic Atlas is a renewed and updated version of the original "Spain through maps", a didactic resource created more than ten years ago. Like that previous version, the contents of the Didactic Atlas are based on the National Atlas of Spain and other materials from the IGN, adapted to the didactic context and the educational levels.

The focus is placed on interactive cartography, which allows students to navigate, combine different layers of geographic information, consult the associated alphanumeric and thematic information, and create their own maps. Apart from maps, the Atlas includes theoretical and multimedia contents, and it is complemented with didactic activities. The objective is to support the self-learning, the use of Geographic Information Systems and the Information and Communications Technologies.

The materials have been created considering the curriculum of the Spanish educational system (Real Decreto 1105/2014, de 26 de diciembre, por el que se establece el currículo básico de la Educación Secundaria Obligatoria y del Bachillerato) so that it can be used as a resource for Geography teachers.

The Didactic Atlas is made up of 15 topics, each one dedicated to one of the learning standards established by the Spanish regulation, plus a glossary of geographical terms.

1. The representation of the territory in plans and maps

2. The great units of the Spanish relief

3. The climatic variety of Spain

4. The distribution of vegetation in Spain

5. The waters in Spain

6. Characteristics of Spanish landscapes

7. Population: Who are we and where do Spaniards live?

8. People on the move: migratory movements in Spain.

9. The characteristics of Spanish cities in their urban plan

10. Spain: a network of cities in a mostly rural territory

11. Agricultural uses in Spain

12. Location of the Spanish industry

13. Spatial analysis of the main economic sector in Spain: services

14. Origin and development of the current Spanish territorial organization

15. The international relations of Spain in the world 
The process of creation of the Didactic Atlas comprises different tasks:

- Creating the theoretical basis: Made in collaboration with the Group of Didactic of Geography of the Spanish Association of Geography. More than 60 secondary, high school and university teachers from practically all the Spanish regions have participated assembled in 16 working groups. They were coordinated by a manager group made up of teachers, and professionals from the National Geographic Institute.

- Publishing web map services and map viewers: a wide variety of maps from the National Atlas of Spain and new derived ones are being published through web services. Map viewers are the windows which allow searching for toponyms, navigation, layering, measurement, creating longitudinal profiles, swiping the screen to simultaneously view two different layers, etc.

- Establishing the web platform that hosts all the contents and makes them available to teachers and students. A free and open source software has been chosen: eXeLearning, which is a free software tool under GPL-2 licence to create educational resources.

The Didactic Atlas by IGN Spain will be available at Educa IGN, the IGN website for educational resources. It will be an Open Educational Resource as defined by UNESCO: digital, for free, under an open licence that permits use, adaptation, and redistribution by others with no restrictions, respecting the authorship of the work. 